\title{
Should We Report Incidental Low-Density Liver Lesions with Benign Features? A Retrospective Single-Center Analysis of Trauma CT Scans
}

\author{
Bob Zhang ${ }^{1}$ Prasanna Ratnakanthan ${ }^{1, \odot}$ Maryam Shekarforoush ${ }^{1} \quad$ Warren Clements ${ }^{1,2,3, \odot}$ \\ ${ }^{1}$ Department of Radiology, Alfred Hospital, Melbourne, Victoria, \\ Australia \\ 2Department of Surgery, Central Clinical School, Monash University, \\ Clayton, Victoria, Australia \\ Address for correspondence Warren Clements, BBiomedSc (Hons), \\ MBBS, FRANZCR, EBIR, Department of Radiology, Alfred \\ Health, Phillip Block, Level 1, 55 Commercial Road, Melbourne \\ Victoria 3004, Australia (e-mail: w.clements@alfred.org.au).
}

${ }^{3}$ National Trauma Research Institute, Monash University, Clayton, Victoria, Australia

J Gastrointestinal Abdominal Radiol ISGAR 2021;4:24-27.

\begin{abstract}
Keywords

- Incidental

- liver

- benign

- cyst

- trauma

Background Many incidental liver lesions are benign and require no additional workup. Investigation of such lesions can have a negative impact of both the patient and health care system. However, the impact of how radiologists report these incidental lesions is not clear. We aimed to investigate how reporting of incidental liver lesions on trauma computed tomography (CT) scan affects follow-up.

Methods This is a retrospective single-center analysis of body CT scans performed following abdominal trauma. Information was collected on the reporting of incidental low-density liver lesions and any additional imaging performed.

Results A total of 3,595 trauma body CT scan reports were reviewed. Incidental liver lesions were identified in 527 (15\%) patients, with 347 (10\%) fulfilling the inclusion criteria. Additional imaging was requested by the referring doctor for 43 out of 285 patients (15\%) when lesions were mentioned in the body of the report only, compared with 41 out of 62 patients $(66 \%)$ when mentioned in the conclusion (odds ratio [OR] $=10.99$, $p<0.0001)$. When additional imaging was recommended in the report, follow-up was arranged for 36 out of 52 patients (69\%), compared with 48 out of 285 patients (16\%) when it was not suggested $(O R=11.58, p<0.0001)$. Additional imaging was requested for 84 of the 347 patients (24\%), with 24 of these performed at our institution. All patients followed-up at our institution were diagnosed with a benign lesion.

Conclusion Reporting incidental hypodense liver lesions in the conclusion or specifically recommending further additional imaging, both led to significantly increased likelihood of additional imaging being performed. Radiologists who encounter such lesions should consider excluding them from the conclusion if there are no malignant features or patient risk factors.
\end{abstract}

\section{Introduction}

Computed tomography (CT) in the trauma setting is a vital tool to allow early detection of intra-abdominal injuries. However, the increased use of cross-sectional imaging has also resulted in increased detection of incidental findings,

published online October 22, 2020
DOI https://doi.org/ $10.1055 / \mathrm{s}-0040-1718250$ ISSN 2581-9933. with reported frequency of up to $53 \%^{1}$; and some studies even show a higher incidence of incidental findings than traumatic injuries on trauma abdominal CT scans. ${ }^{2}$

Although incidental findings can be clinically significant, it is well reported in the literature that the majority
(C2020. Indian Society of Gastrointestinal and Abdominal Radiology. This is an open access article published by Thieme under the terms of the Creative Commons Attribution-NonDerivative-NonCommercial-License, permitting copying and reproduction so long as the original work is given appropriate credit. Contents may not be used for commercial purposes, or adapted, remixed, transformed or built upon. (https://creativecommons.org/licenses/by-nc-nd/4.0/).

Thieme Medical and Scientific Publishers Pvt. Ltd. A-12, 2nd Floor, Sector 2, Noida-201301 UP, India 
of incidental findings on trauma CTs are benign and do not require further investigation or intervention. ${ }^{1-6}$ Inappropriate management of incidental findings can lead to unnecessary additional investigations, potentially risky interventions, increased exposure to ionizing radiation, increased patient anxiety, increased length of hospital stay, and increased burden on the health care system. ${ }^{6-8}$

Liver lesions are a commonly encountered incidental finding on CT. ${ }^{9,10}$ These lesions can often be confidently diagnosed based on characteristic imaging features, such as sharp margins and homogeneous low attenuation ( $<20$ Hounsfield's units [HU]) on noncontrast or portal venous phase imaging. ${ }^{11}$ Additionally, lesions which cannot be fully characterized on CT and are deemed "indeterminate" have also been shown to have a low (1\%) risk of malignancy, ${ }^{9}$ with the majority eventually diagnosed as cysts or hemangiomas. The American College of Radiology (ACR) White Paper on management of incidental liver lesions recommends against further investigation for incidental liver lesions less than $1 \mathrm{~cm}$ in low-risk patients, and lesions with distinctively benign imaging features. They define low risk patients as those with no known malignancy, no hepatic dysfunction, and no other hepatic risk factors. ${ }^{11}$ When further investigated, it has been shown that benign liver lesions require more follow-up time and repeated examinations compared with malignant lesions, and repeated examinations were often redundant. ${ }^{8}$

In our practice, radiologists may choose to recommend further investigations or follow-up of a lesion in the report; however, the ultimate decision to follow-up and the request/ plans for further investigations are made by the referring unit, in line with local guidelines for requesting of imaging studies. We have noticed anecdotally a relatively high frequency of additional imaging for incidental liver lesions with benign and indeterminate features detected on trauma CT scans. These lesions may not need additional imaging as defined in the ACR White Paper. However, we have also noticed marked heterogeneity in the reporting of such lesions by different radiologists.

The aim of this study was to investigate the frequency of incidental liver lesions on trauma CT scans, frequency of additional imaging investigations being performed for hypodense lesions with benign imaging features, and whether differences in reporting of such lesions influenced follow-up.

\section{Methods}

Approval for the study was obtained by our institutional review board including a waiver of informed consent. This was a retrospective single-center analysis of trauma body CT scans performed at the Alfred Hospital between June 1, 2018 and September 1, 2019. All CT scans were performed on 320-detector row CT scanners; Canon Aquilion Genesis and Canon Aquilion One (Canon Medical Systems Corporation, Otawara, Japan). The injection protocol was $80 \mathrm{~mL}$ OM350 at $4 \mathrm{~mL} / \mathrm{s}$ (portal venous phase), 22-second delay, $40 \mathrm{~mL}$ OM350 at $4 \mathrm{~mL} / \mathrm{s}$ (arterial phase). This generates a dual-injection, single-pass acquisition of chest-abdomen-pelvis with thoracic and lumbar spine reconstructions (from thoracic inlet to pubic symphysis).

The Radiology Information System (RIS) and Picture and Communications Archive (PACS) were used to identify all patients who underwent abdominal CT in the emergency department for the purposes of identification of traumatic injuries. The hospital electronic medical record (EMR) was then identified. Information was collected on reporting of incidental low-density liver lesions with benign features, defined as lesions <20 HU and with sharp margins (-Fig. 1A, B), and images were checked by an additional radiologist (study investigator), in addition to the initial reporting radiologist. Information that was collected included whether the lesion was reported within the body and/or conclusion of the report, description of the lesion (including size and density), further investigations that were recommended in the report, further investigations that were ordered, and the results of those investigations.

Exclusion criteria included lesions which were identified as being high density (higher density than the background liver parenchyma), related to perfusion changes, focal fatty sparing/infiltration, patients with known malignancy or comparable prior imaging, and patients who died during their admission. The records of included patients were then searched to identify follow-up of the lesion with a method considered to be gold standard for that patient (e.g., ultrasound, triphasic CT, or biopsy depending on the lesion characteristics) to obtain a definitive diagnosis ( - Fig. 1C).

Results were pooled and analysis was performed using Microsoft Excel (Microsoft, Redmond, Washington, United States) with real statistics add on. Data are presented
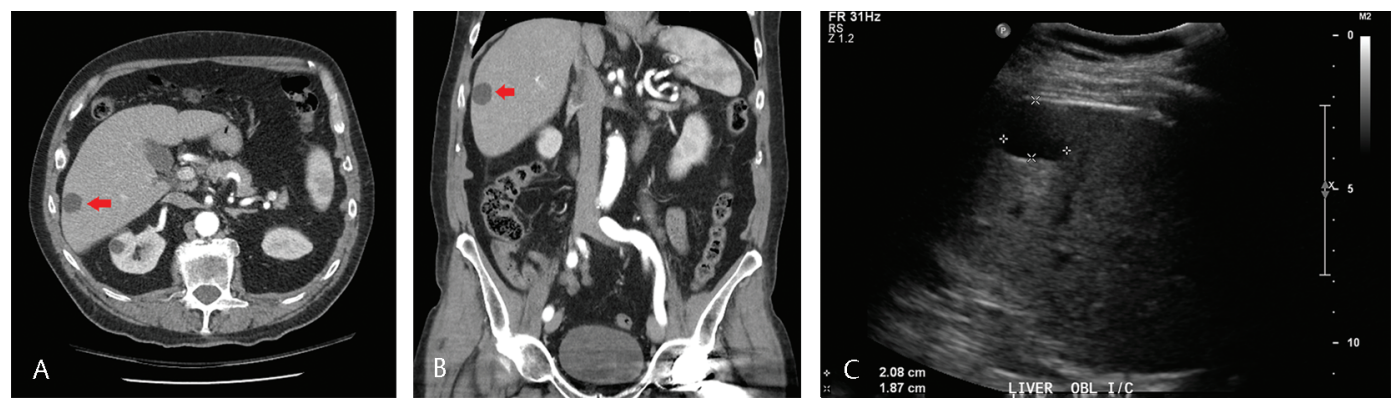

Fig. 1 (A, B), Axial contrast enhanced CT through upper abdomen (A) and coronal reformation (B) show a well-defined sharply marginated hypodense lesion in peripheral portion of segment 6 of the liver (arrow) measuring $21 \mathrm{~mm}$ (CT attenuation 15 HU). A diagnosis of cyst was suggested. (C) Ultrasound in intercostal oblique sagittal view of liver, performed 4 days later, shows a simple cyst corresponding to CT. No further follow-up was necessary. CT, computed tomography; HU, Hounsfield's units. 
as numbers and percentages, median (range, low-high), or mean ( \pm standard deviation) relevant to the type of data. Statistical analysis was performed using Pearson's Chi-square test for independence with results reported as odds ratio (OR) and $p$-values, or Fisher's exact test with results reported as $p$-value. A p-value of less than 0.05 was considered statistically significant.

\section{Results}

A total of 3,595 trauma body CT scans were performed during the study period and all scan reports were reviewed. Incidental liver lesions were reported in 527 (15\%) patients, with 347 lesions (10\%) fulfilling the inclusion criteria for the study ( - Fig. 2). Patient and lesion demographics are shown in - Table 1. Of the included lesions, the majority were reported as likely benign lesions $(311,90 \%)$ with $36(10 \%)$ reported as either indeterminate hypodense lesions, or a diagnosis was not offered in the report.

As shown in - Table 2, when the liver lesion was mentioned in the body of the report only, additional imaging was ordered for 43 out of 285 patients (15\%), however, when mentioned in the conclusion of the report, imaging follow-up was ordered in 41 out of 62 patients (66\%), OR of 10.99 and $p<0.0001$.

When additional imaging was specifically recommended in the report, this was ordered by the referring unit for 36 out of 52 patients (69\%) compared with when it was not suggested in 48 out of 295 patients (16\%), OR of 11.58 and $p<0.0001$.

Overall, additional imaging was arranged by the referring trauma unit for 84 of the 347 patients (24\%). A total of 24 of these patients were followed-up at our institution while the remaining 60 patients had imaging organized elsewhere with results not available for these patients. Additional imaging

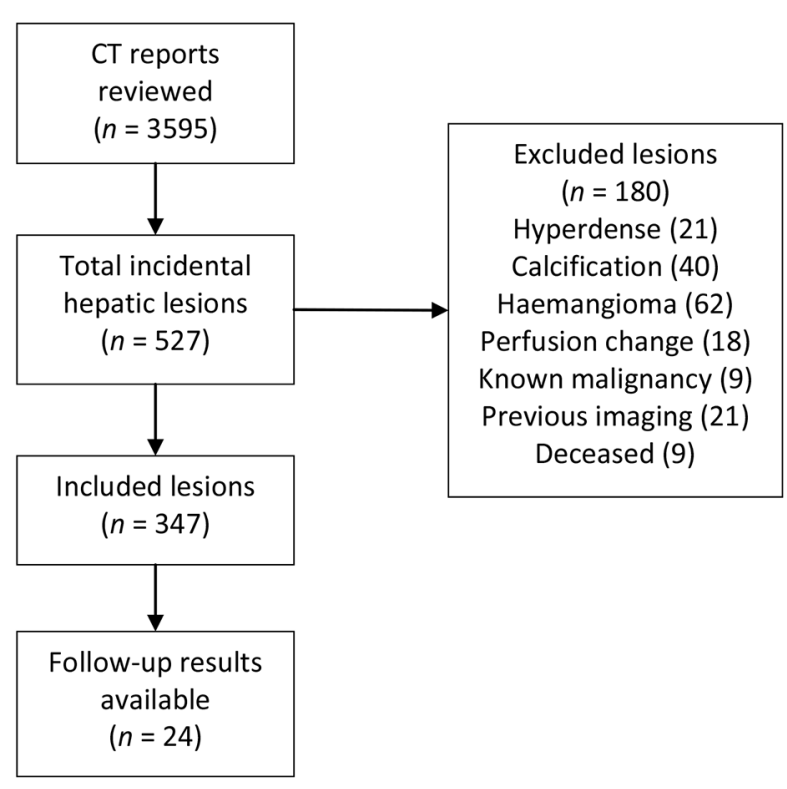

Fig. 2 Flow chart identifying lesion selection for the study.
Table 1 Demographics and lesion outcomes of patients included in the study

\begin{tabular}{|l|l|}
\hline $\begin{array}{l}\text { Total patients with incidental hypodense liver } \\
\text { lesion on CT }\end{array}$ & 347 \\
\hline $\begin{array}{l}\text { Patients with liver lesion followed-up } \\
n(\%)\end{array}$ & $84(24.2)$ \\
\hline $\begin{array}{l}\text { Patients with additional imaging at our } \\
\text { institution } \\
n(\%)\end{array}$ & $24(6.9)$ \\
\hline $\begin{array}{l}\text { Age (y) } \\
\text { Mean } \pm \text { SD }\end{array}$ & $64 \pm 18.2$ \\
\hline Male gender (\%) & 60.8 \\
\hline Malignant liver lesions identified ${ }^{\text {(\%) }}$ & 0 \\
\hline Benign liver lesions identifieda (\%) $^{\circ}$ & 100 \\
\hline $\begin{array}{l}\text { Liver lesion size }{ }^{a} \text { (mm) } \\
\text { Median (range) }\end{array}$ & $12.5(4-43)$ \\
\hline $\begin{array}{l}\text { Liver lesion density }{ }^{a} \text { (Hounsfield's units) } \\
\text { Median (range) }\end{array}$ & $30(1-60)$ \\
\hline
\end{tabular}

Abbreviations: CT, computed tomography; SD, standard deviation.

aLesions with additional imaging at our institution.

Table 2 Rates of follow-up of lesions based on radiologist reporting

\begin{tabular}{|l|c|}
\hline $\begin{array}{l}\text { Percentage of additional imaging of lesion when } \\
\text { mentioned in body of report }\end{array}$ & 15 \\
\hline $\begin{array}{l}\text { Percentage of additional imaging of lesion when } \\
\text { mentioned in conclusion of report }\end{array}$ & $66^{\mathrm{a}}$ \\
\hline $\begin{array}{l}\text { Percentage of additional imaging of lesion when follow-up } \\
\text { recommendation not given }\end{array}$ & 16 \\
\hline $\begin{array}{l}\text { Percentage of additional imaging of lesion when follow-up } \\
\text { specifically recommended }\end{array}$ & $69^{\mathrm{b}}$ \\
\hline
\end{tabular}

${ }^{\text {a Odds ratio }=10.99, p<0.0001}$

'Odds ratio $=11.58, p<0.0001$

was performed at a median of 5 days (range: 1-87 days) after the initial CT scan. Ultrasound was used in all patients.

The median size of the followed-up lesions was $12.5 \mathrm{~mm}$ (range: 4-43 mm)and median density $30 \mathrm{HU}$; range: 1-60 HU). Of the 24 lesions followed-up at our institution, 16 were reported as likely cysts on $\mathrm{CT}$, and these were all diagnosed as simple cysts on follow-up ultrasound with a median size of $14.5 \mathrm{~mm}$ and density of $17.5 \mathrm{HU}$. The remaining eight lesions were reported as either indeterminate hypodense lesions or a diagnosis not offered. Of these, five were diagnosed as simple cysts on ultrasound, one as a hemangioma, and the remaining two lesions could not be seen on ultrasound (subcentimeter) and were not further investigated. The median size in this group was $7 \mathrm{~mm}(p=0.07)$ and density $31 \mathrm{HU}(p=0.34)$.

\section{Discussion}

Benign liver lesions have characteristic imaging features, and in most instances can be confidently diagnosed on CT. ${ }^{11}$ In addition, hypodense liver lesions which are too small to be confidently characterized on CT are also almost always benign and are can usually diagnosed as cysts or hemangiomas with 
additional imaging. ${ }^{7}$ As recommended in the ACR White Paper on management of liver lesions, any lesion with distinctly benign imaging features and indeterminate lesions without suspicious imaging features in low-risk patients do not require any further workup.

Our study identified a significantly higher rate of follow-up $(\mathrm{OR}=10.99)$ if the lesion was mentioned in the conclusion of the report (66\% compared with $18 \%$ if not mentioned, $p<0.0001)$ and if further investigations were suggested within the report (69\% compared with $16 \%$ if not mentioned, $\mathrm{OR}=11.58, p<0.0001)$. This highlights significant potential to reduce unnecessary burden associated with follow-up by not specifically recommending further investigations for characteristically benign liver lesions and excluding them from the conclusion. Similar observations have been made in studies on incidental liver lesions on breast magnetic resonance imaging (MRI). DiPiro et $\mathrm{al}^{12}$ compared breast and abdominal subspecialists' follow-up recommendations for incidental liver lesions on MRI, and found that abdominal subspecialists disagreed with 28 of 30 breast subspecialist follow-up recommendations, and in cases where the referring clinician followed breast subspecialists' recommendations for further imaging, 94\% of lesions were benign. Knox et $\mathrm{al}^{13}$ assessed the characteristics of incidental liver lesions on breast MRI and found that no lesions with characteristic imaging features were clinically significant at follow-up, and concluded that if recommendations to not follow-up for such lesions were implemented, the rate of additional imaging would have reduced from 37.3 to $5.3 \%$.

In this study, incidental hypodense liver lesions were identified on $10 \%$ of trauma CT scans, with the majority characterized by the reporting radiologist on $\mathrm{CT}$ as either cysts or hemangiomas (90\%). All lesions with additional imaging at this institution confirmed this diagnosis. This is consistent with data reported in other studies of both trauma ${ }^{3,5}$ and nontrauma ${ }^{22,13}$ scans. The majority of patients were organized to be followed-up in the community with an abdominal ultrasound, and unfortunately, we were unable to access these results for this study. Of the 24 lesions further investigated at our institution, no lesions were determined to have a malignant etiology.

\section{Limitations}

The authors acknowledge several limitations to this study. First, the study was a single-center retrospective study and practice of reporting and follow-up is limited to the consensus of those at this center with wide variability between medical practices of different doctors. In addition, many of the 84 identified lesions were lost to follow-up (either not performed or performed at another institution with results not able to be confirmed), and as such only a small number of patients were able to have a definitive diagnosis.

\section{Conclusion}

In conclusion, reporting benign-appearing incidental liver lesions as part of the conclusion or specifically recommending further follow-up lead to a greater than 10-time increase in the likelihood of additional investigations being ordered. In addition, the findings of this study support consensus recommendations that small lesions less than $30 \mathrm{HU}$ should not be followed-up when they have nonaggressive features and in the absence of known extra-hepatic malignancy or preexisting hepatic risk factors.

The authors suggest radiologists recommend excluding these lesions from the conclusion, or specifically recommending that that additional investigations are not required. Otherwise, this practice can place a burden on the patient and hospital with associated direct and indirect cost implications which may otherwise be avoided.

\section{Funding \\ None.}

\section{Conflict of Interest}

None declared.

\section{References}

1 Barrett TW, Schierling M, Zhou C, et al. Prevalence of incidental findings in trauma patients detected by computed tomography imaging. Am J Emerg Med 2009;27(4):428-435

2 Munk MD, Peitzman AB, Hostler DP, Wolfson AB. Frequency and follow-up of incidental findings on trauma computed tomography scans: experience at a level one trauma center. J Emerg Med 2010;38(3):346-350

3 Sierink JC, Saltzherr TP, Russchen MJ, et al. Incidental findings on total-body CT scans in trauma patients. Injury 2014; 45(5):840-844

4 Paluska TR, Sise MJ, Sack DI, Sise CB, Egan MC, Biondi M. Incidental CT findings in trauma patients: incidence and implications for care of the injured. J Trauma 2007;62(1):157-161

5 Hoffstetter P, Herold T, Daneschnejad M, et al. [Non-traumaassociated additional findings in whole-body CT examinations in patients with multiple trauma] (in German) RoFo Fortschr Geb Rontgenstr Nuklearmed 2008;180(2):120-126

6 Andrawes P, Picon AI, Shariff MA, et al. CT scan incidental findings in trauma patients: does it impact hospital length of stay? Trauma Surg Acute Care Open 2017;2(1):e000101

7 Kuan LL, Mavilakandy A, Oyebola T, Bhardwaj N, Dennison AR, Garcea G. Indeterminate liver lesions - a virtual epidemic: a cohort study over 8 years. ANZ J Surg 2020;90(5):791-795

8 Collin P, Rinta-Kiikka I, Räty S, Laukkarinen J, Sand J. Diagnostic workup of liver lesions: too long time with too many examinations. Scand J Gastroenterol 2015;50(3):355-359

9 Kaltenbach TE, Engler P, Kratzer W, et al. Prevalence of benign focal liver lesions: ultrasound investigation of 45,319 hospital patients. Abdom Radiol (NY) 2016;41(1):25-32

10 Kumada K, Murakami N, Okada H, Toyoda I, Ogura S, Asano T. Incidental findings on whole-body computed tomography in trauma patients: the current state of incidental findings and the effect of implementation of a feedback system. Acute Med Surg 2019;6(3):274-278

11 Gore RM, Pickhardt PJ, Mortele KJ, et al. Management of incidental liver lesions on ct: a White Paper of the ACR Incidental Findings Committee. J Am Coll Radiol 2017;14(11):1429-1437

12 DiPiro PJ, Alper DP, Giess CS, et al. Comparing breast and abdominal subspecialists' follow-up recommendations for incidental liver lesions on breast MRI. J Am Coll Radiol 2020;17(6):773-778

13 Knox M, Slanetz P, Phillips J, et al. Incidental liver lesions seen on Breast MRI: When is additional imaging warranted? Eur J Radiol 2017;95:319-324 